\title{
Investigation of Mathematical Concept Skills of Children Trained with Montessori Approach and MoE Pre-school Education Program
}

\author{
Sema Ongoren \\ Nevsehir Haci Bektas Veli University, TURKEY
}

\author{
Derya Ozlem Yazlik * \\ Nevsehir Haci Bektas Veli University, TURKEY
}

Received: September 13, $2018 \cdot$ Revised: October 28, $2018 \cdot$ Accepted: November 5, 2018

\begin{abstract}
In this study, it is aimed to examine the mathematical conceptual skills of 48-72-month-old children attending pre-school education institutions providing a Montessori Approach and Ministry of Education Pre-school Program (MoE PSP). The study group consisted of 20 children, who were trained by the Montessori Approach, and 20 children, who continued to attend pre-school education institutions applying the MoE PSP. The research was carried out in accordance with the state study design of the qualitative research methods, and the data of the study was collected by the structured observation method at the free play/individual work time in the learning centers of the children constituting the study group. A structured observation form was used as the data gathering tool, and mathematical concept skills such as counting, matching, grouping, comparison, positioning, measurement, pattern, part-whole, transactions and creating a graphic were included. Research data were analyzed with descriptive analysis method, and the frequency and percentage values of the obtained data were calculated. As a result of the study, it was observed that the students trained with the Montessori Approach and MoE PSP could not create graphics in both groups while the rhythmic counting and patterning skills were the most frequently observed skills in children. It has been determined that children are trained with the Montessori Approach complete more studies, especially on matching, grouping, comparison/ranking, and partwhole skills, compared to the children trained with MoE PSP. In the light of the results obtained in this research, it is suggested that the play materials that had to be in classes where MoE PSP was applied should be standardized, and children should be able to get through these materials; also mathematics center should be established in the class level.
\end{abstract}

Keywords: Montessori approach, pre-school education, pre-school education program, Mathematics education, Mathematical concepts.

To cite this article: Ongoren, S, \& Yazlik, D. O. (2019). Investigation of mathematical concept skills of children trained with montessori approach and MoE pre-school education program. European Journal of Educational Research, 8(1), 9-19. doi: 10.12973/eu-jer.8.1.9

\section{Introduction}

Mathematics, especially problem solving, creative thinking, and communication, which is one of the first experiences of children from early ages, is a crucial experience at every level. From early childhood, mathematics can be learned not only from activities focusing on the development of certain mathematical knowledge and skills but also from other activities related to numbers, shapes, and patterns in children's daily life and environments (Haylock and Cockburn, 2014). Mathematical thinking is a natural ability in children, just like speech; but it must be guided by the child's developmental stages to develop positively. With the mathematical activities applied, the children should be able to recognize the patterns in their environment, develop hypotheses, communicate using problem-solving, reasoning, and mathematical concepts (Ministry of Education [MoE], 2013; Wilbrandt, 2009). For this reason, early childhood education programs should include activities considering knowledge, skills, and attitudes that children may need in life and higher education (Kandir, Can Yasar, Yazici, Turkoglu and Yaman-Bayindir, 2016).

Mathematical activities which are developed for healthy growth of children who attend MoE pre-school educational institutions in Turkey to provide support in all development areas and to make them ready for elementary school accelerates the child's creative thinking, mental estimation, and learning by concretizing abstract concepts (Mutlu, Ergisi, Butun-Ayhan and Aral, 2012; MoE, 2013). Mathematical activities should be transformed into a process that the children discover, rather than an activity in which information is repeated and memorized. An active learning process should be created to encourage children to explore mathematics through play (Erdogan, 2016). Researches show that meaning-based learning is more permanent than learning by heart and recurrence, psychologically more satisfying, and more useful in practice (Haylock and Cockburn, 2014).

\footnotetext{
* Corresponding author:

Derya Ozlem Yazlik, Nevsehir Haci Bektas Veli University, Department of Mathematics and Science Education, Nevsehir / Turkey

$\triangle$ doyazlik@nevsehir.edu.tr
} 
The Montessori Approach, which is one of the alternative approaches applied in pre-school education, is an approach which gives importance of the child's sense, movement, and language education; and contributes to their social, emotional, and physical development (Oguz and Akyol, 2006). Montessori Approach has different materials which are structured according to the "self-education" principle in the learning environment and support the development of children (Durakoglu, 2010; Toran and Temel, 2012; Wilbrandt, 2009). The mathematics materials, one of the materials in Montessori classes, are developed according to M. Montessori Piaget's "internalization of structures and outward transformation of internal actions" thought and called them all the problem-solving intelligence (Buyuktaskapu, 2011). The most important feature of the mathematical materials used in the Montessori Approach is to concretizing abstract concepts. At the same time, the materials have a particular order, and all concepts are taught to the child in a simple to complicated, concrete to abstract order (Wilbrandt, 2009).

In the early years, the support of children's mathematical concept skills is made possible by mathematical content arrangements that are appropriate to the developmental characteristics of children. These mathematical contents consist of mathematical activities related to the skills of establishing relations, matching, grouping, patterning, ranking, counting, adding and subtracting, recognizing geometrical shapes (symbols), and preparing graphics. These skills form the basis of children's structuring of mathematical ideas and thoughts, and they are the prerequisites of each other. For the development of mathematical skills of children, pre-school teachers should provide active participation by organizing activities such as matching, classifying, comparing, ranking (Kandir et al., 2016; Unal, 2016).

Within this scope, because of the limited number of studies on mathematical concepts in the pre-school education program of Moe updated in 2013, the gradual increase in the number of pre-school education organizations implementing the Montessori Approach which is presented as an alternative in pre-school education in Turkey increases the need for current studies related to this field. For this reason, it is aimed to investigate the mathematical conceptual skills of children trained with Montessori Approach and Ministry of Education preschool education program in this research.

\section{Method}

The study aimed to examine mathematical conceptual skills such as counting, matching, grouping, comparison, position, measurement, pattern, part-whole, transactions, and graphing of children at the age of 48-72 months who got an education with Montessori Approach and Ministry of Education Pre-school Program (MoE PSP). To this end, research has been conducted by the case study design of qualitative research methods. The case study is a study that examines the current situation in real life contexts when the boundaries between case and context are not fully understood (Yin, 2008).

\section{Study Group}

The study group consisted of 40 children in total, 20 children who were 48-72 months old and getting an education with the Montessori Approach at city Centre in Turkey, and 20 children who were 48-72 months old and getting preschool education institutions practicing MoE PSP. 20 of the children were female, and 20 of them were male. 11 (58\%) children at Montessori classes were 48-60 months old, 9 (45\%) of them were 61-72 months old. 6 of the girls in this group were 48-60 months old, 4 of them were 61-72 months old while 5 of the boys were 48-60 months old and 5 of them were 61-72 months old. 9 (45\%) of the children in the MoE PSP classes were 48-60 months old, and 11 (55\%) of them were 61-72 months old. In this group, 4 of the girls were 48-60 months old, 6 of them were $61-72$ months old; while 5 of the boys were 48-60 months old, and 5 of them were 61-72 months old. The study group was determined based on a convenience sampling method, one of the purposeful sampling methods (Merriam, 2013).

\section{Data Collection Tool}

For the collection of the research data, interviews were conducted with the school administrators, and the classes to be observed were determined, then interviewing with the volunteer teachers, the appropriate time interval was determined, and the schools were visited for observation. Children in the Montessori class were observed during the time of the individual study with Montessori materials between 10:00-11:00 am., and the children in classrooms practicing MoE PSP were observed during free play activity with table and concept toys time between 10:00-11:00 am. Each child was observed by researchers three times with twenty minutes of simultaneous and independent observation. The reason why the observations carried out during the individual study and free play activities was being able to determine the different skills children's have. Because the mathematical activities in the classes in which MoE PSP is applied are limited, and like group study, free play time is preferred to observe the skills of these children individually. The researchers filled out observation forms during the classroom observations, taking the mathematical concept skills determined through the activities children to do with materials/toys and their communication within the classroom into consideration. At the same time, researchers also kept notes about the behaviors related to children's skills in the observation process. 
Analysis of Data

Descriptive analysis was used in the analysis of data obtained through observation. The data obtained were interpreted according to the previously determined categories. During this descriptive analysis, the conceptual framework was established by drawing out the dimensions of the observation form, and the thematic framework was determined. The data were interpreted according to the created frame (Yildirim and Simsek, 2011).

While the observation data were being analyzed, the observation forms were examined to see whether there was a conformity between observers. When the agreement percentage formula by Miles and Huberman (1994) was used, it was determined that consensus was achieved in the rate of $94 \%$. In cases where there was no conformity between researchers, a consensus was reached by checking the observation notes. Also, the data collection process and the data obtained were explained in detail using the direct citation to ensure reliability and validity.

\section{Results}

As a result of the observation, mathematical concept skills are divided into categories of counting, matching, grouping, comparison, position, measurement, pattern, part-whole, transactions, creating graphics and then the frequency and percentage values are given in Table and interpreted. 
Table1. The Distribution of Mathematical Concept Skills

\begin{tabular}{|c|c|c|c|c|c|c|c|c|c|c|c|c|c|c|c|c|c|c|c|c|c|}
\hline \multirow{3}{*}{$\begin{array}{l}\text { Mathematical } \\
\text { Concept Skills }\end{array}$} & \multirow{3}{*}{$\begin{array}{c}\text { Sub- } \\
\text { Categories }\end{array}$} & \multicolumn{10}{|c|}{ Montessori Approach } & \multicolumn{10}{|c|}{ MoE Pre-school Education Program } \\
\hline & & \multicolumn{2}{|c|}{ F5 } & \multicolumn{2}{|c|}{ F6 } & \multicolumn{2}{|c|}{ M5 } & \multicolumn{2}{|c|}{ M6 } & \multicolumn{2}{|c|}{ Total } & \multicolumn{2}{|c|}{ F5 } & \multicolumn{2}{|c|}{ F6 } & \multicolumn{2}{|c|}{ M5 } & \multicolumn{2}{|c|}{ M6 } & \multicolumn{2}{|c|}{ Total } \\
\hline & & f & $\%$ & f & $\%$ & f & $\%$ & $\mathbf{f}$ & $\%$ & f & $\%$ & f & $\%$ & $\mathbf{f}$ & $\%$ & f & $\%$ & f & $\%$ & f & $\%$ \\
\hline 1. Rhythmic counting & & 3 & 50.0 & 4 & 100 & 5 & 100 & 3 & 60.0 & 15 & 75.0 & 3 & 75.0 & 5 & 83.3 & 3 & 60.0 & 4 & 80.0 & 15 & 75.0 \\
\hline \multirow{5}{*}{ 2. Matching } & Figure & 6 & 100 & 3 & 75.0 & 2 & 40.0 & 2 & 40.0 & 13 & 65.0 & 1 & 25.0 & 1 & 16.7 & 5 & 100 & 1 & 20.0 & 8 & 40.0 \\
\hline & Size & 0 & 0.0 & 1 & 25.0 & 0 & 0.0 & 0 & 0.0 & 1 & 5.0 & 0 & 0.0 & 0 & 0.0 & 0 & 0.0 & 0 & 0.0 & 0 & 0.0 \\
\hline & Weight & 0 & 0.0 & 0 & 0.0 & 0 & 0.0 & 0 & 0.0 & 0 & 0.0 & 0 & 0.0 & 0 & 0.0 & 0 & 0.0 & 2 & 40.0 & 2 & 10.0 \\
\hline & Length & 0 & 0.0 & 0 & 0.0 & 1 & 20.0 & 1 & 20.0 & 2 & 10.0 & 0 & 0.0 & 0 & 0.0 & 0 & 0.0 & 0 & 0.0 & 0 & 0.0 \\
\hline & Quantity & 1 & 16.7 & 2 & 50.0 & 2 & 40.0 & 2 & 40.0 & 7 & 35.0 & 0 & 0.0 & 2 & 33.3 & 0 & 0.0 & 1 & 20.0 & 3 & 15.0 \\
\hline \multirow{5}{*}{ 3. Grouping } & Figure & 3 & 50.0 & 2 & 50.0 & 4 & 80.0 & 4 & 80.0 & 13 & 65.0 & 4 & 100 & 4 & 66.7 & 4 & 80.0 & 4 & 80.0 & 12 & 60.0 \\
\hline & Size & 1 & 16.7 & 0 & 0.0 & 2 & 40.0 & 1 & 20.0 & 4 & 20.0 & 0 & 0.0 & 0 & 0.0 & 0 & 0.0 & 0 & 0.0 & 0 & 0.0 \\
\hline & Weight & 0 & 0.0 & 0 & 0.0 & 0 & 0.0 & 0 & 0.0 & 0 & 0.0 & 0 & 0.0 & 0 & 0.0 & 0 & 0.0 & 0 & 0.0 & 0 & 0.0 \\
\hline & Length & 0 & 0.0 & 0 & 0.0 & 0 & 0.0 & 0 & 0.0 & 0 & 0.0 & 0 & 0.0 & 0 & 0.0 & 0 & 0.0 & 0 & 0.0 & 0 & 0.0 \\
\hline & Quantity & 1 & 16.7 & 1 & 25.0 & 2 & 40.0 & 2 & 40.0 & 6 & 30.0 & 0 & 0.0 & 0 & 0.0 & 0 & 0.0 & 0 & 0.0 & 0 & 0.0 \\
\hline \multirow{5}{*}{$\begin{array}{l}\text { 4.Comparison } \\
\text { /Ranking }\end{array}$} & Figure & 6 & 100 & 4 & 100 & 2 & 40.0 & 3 & 60.0 & 15 & 75.0 & 2 & 50.0 & 1 & 16.7 & 5 & 100 & 0 & 0.0 & 8 & 40.0 \\
\hline & Size & 3 & 50.0 & 3 & 75.0 & 1 & 20.0 & 0 & 0.0 & 7 & 35.0 & 0 & 0.0 & 0 & 0.0 & 0 & 0.0 & 0 & 0.0 & 0 & 0.0 \\
\hline & Weight & 0 & 0.0 & 1 & 25.0 & 0 & 0.0 & 1 & 20.0 & 2 & 10.0 & 0 & 0.0 & 0 & 0.0 & 0 & 0.0 & 1 & 20.0 & 1 & 5.0 \\
\hline & Length & 2 & 33.3 & 0 & 0.0 & 1 & 20.0 & 3 & 60.0 & 6 & 30.0 & 0 & 0.0 & 0 & 0.0 & 0 & 0.0 & 0 & 0.0 & 0 & 0.0 \\
\hline & Quantity & 1 & 16.7 & 2 & 50.0 & 1 & 20.0 & 1 & 20.0 & 5 & 25.0 & 0 & 0.0 & 0 & 0.0 & 0 & 0.0 & 0 & 0.0 & 0 & 0.0 \\
\hline \multirow{2}{*}{ 5.Position in Space } & Direction & 1 & 16.7 & 0 & 0.0 & 1 & 20.0 & 1 & 20.0 & 3 & 15.0 & 0 & 0.0 & 0 & 0.0 & 0 & 0.0 & 0 & 0.0 & 0 & 0.0 \\
\hline & Close-Far & 0 & 0.0 & 0 & 0.0 & 0 & 0.0 & 0 & 0.0 & 0 & 0.0 & 0 & 0.0 & 0 & 0.0 & 0 & 0.0 & 0 & 0.0 & 0 & 0.0 \\
\hline \multirow{4}{*}{ 6. Measurement } & Time & 0 & 0.0 & 0 & 0.0 & 0 & 0.0 & 0 & 0.0 & 0 & 0.0 & 0 & 0.0 & 0 & 0.0 & 0 & 0.0 & 0 & 0.0 & 0 & 0.0 \\
\hline & Length & 0 & 0.0 & 0 & 0.0 & 1 & 20.0 & 2 & 40.0 & 3 & 15.0 & 0 & 0.0 & 0 & 0.0 & 0 & 0.0 & 0 & 0.0 & 0 & 0.0 \\
\hline & Weight & 0 & 0.0 & 0 & 0.0 & 0 & 0.0 & 0 & 0.0 & 0 & 0.0 & 0 & 0.0 & 0 & 0.0 & 0 & 0.0 & 1 & 20.0 & 1 & 5.0 \\
\hline & Money & 0 & 0.0 & 0 & 0.0 & 0 & 0.0 & 0 & 0.0 & 0 & 0.0 & 0 & 0.0 & 0 & 0.0 & 0 & 0.0 & 0 & 0.0 & 0 & 0.0 \\
\hline 7. Pattern & & 4 & 66.7 & 4 & 100 & 3 & 60.0 & 3 & 60.0 & 14 & 70.0 & 4 & 100 & 3 & 50.0 & 5 & 100 & 2 & 40.0 & 14 & 70.0 \\
\hline 8. Part-whole & & 3 & 50.0 & 4 & 100 & 4 & 80.0 & 4 & 80.0 & 15 & 75.0 & 2 & 50.0 & 0 & 0.0 & 1 & 20.0 & 0 & 0.0 & 3 & 15.0 \\
\hline \multirow{2}{*}{ 9. Transactions } & Increase & 0 & 0.0 & 2 & 50.0 & 2 & 40.0 & 1 & 20.0 & 5 & 25.0 & 0 & 0.0 & 2 & 33.3 & 0 & 0.0 & 2 & 40.0 & 4 & 20.0 \\
\hline & Reduction & 0 & 0.0 & 1 & 25.0 & 1 & 20.0 & 1 & 20.0 & 3 & 15.0 & 0 & 0.0 & 1 & 16.7 & 0 & 0.0 & 1 & 20.0 & 2 & 10.0 \\
\hline 10.Creating Graphics & & 0 & 0.0 & 0 & 0.0 & 0 & 0.0 & 0 & 0.0 & 0 & 0.0 & 0 & 0.0 & 0 & 0.0 & 0 & 0.0 & 0 & 0.0 & 0 & 0.0 \\
\hline
\end{tabular}


When Table 1 was examined, it was determined that children who were trained with the Montessori Approach had the rhythmic counting (75\%), comparing / ranking by shape (75\%), part-whole (75\%), and patterning skills most. The least observed skills were the ones towards matching according to length (10\%) and size (5\%) and comparing according to weight (10\%). Besides, matching and grouping according to weight; grouping according to length; closefar; time, weight and money measurement and graphing skills were never encountered in the observation process.

It was determined that the children who were observed in the free play activities in the learning centers and trained with the MoE PSP had more activities towards rhythmic counting (75\%) and pattern (70\%) skills. The least observed skills were the ones towards measurement according to length (10\%), decrease-reduction (10\%) and weight measurement (5\%). Matching size and length during observations; size, weight, length, quantity grouping, and comparison; position in space (direction, close-far); time, length, money, and graphing skills had never seen.

When these findings were examined, it was found that the most observed skills in children who were trained with both Montessori Approach and MoE PSP were the ones towards rhythmic counting and creating a pattern. Also, weight and length grouping; close-far; time, money, and measurement and graphing skills in the children who were trained with both Montessori Approach and MoE PSP were not found during observations.

The mathematical concepts in Table 1 were divided into categories and subcategories, and their findings are given below together with the direct citations.

Rhythmic Counting

Table 2. The Distribution of Children Who Do Activities towards Rhythmic Counting Skills

\begin{tabular}{lc}
\hline Rhythmic counting & f \\
\hline Montessori Approach & 15 \\
MoE Pre-school Education Program & 15 \\
\hline
\end{tabular}

When the results of the observations were examined, it was determined that the most observed skill which children were trained with Montessori Approach and MoE PSP perform was towards developing rhythmic counting skills.

It was observed that 15 of the children who were trained with the Montessori Approach had rhythmic counting skill. It has been determined that 3 of the 48-60 month-old girls, all of the boys, all of the 61-72-month-old girls, and 3 of the boys have this skill.

It was observed that 15 of the children, who were trained with MoE PSP, did activities towards rhythmic counting skill. This skill was found in three girls and three boys at 48-60-months-old; five girls and four boys at 61-72 months-old.

Citations about the rhythmic counting skills observed in children are given below according to gender, age and program;

She brought the sensory materials to the table and counted the material rhythmically to check how many there were before starting to study $(F, 48-60$, Montessori).

During the study, she counted the apple figures on the tray rhythmically ( $F, 48-60$, Montessori).

He counted the different colors of cars in board games rhythmically (M, 61-72, PSP).

He counted the Legos on one side of the rectangle rhythmically to see how many of them there were (M, 61-72, PSP).

Matching

Table3. The Distribution of Children Who Do Activities towards Matching Skills

\begin{tabular}{lccccc}
\hline \multirow{2}{*}{ Matching } & Figure & Size & Weight & Length & Quantity \\
\cline { 2 - 6 } & f & f & f & f & f \\
\hline Montessori Approach & 13 & 1 & 0 & 2 & 7 \\
MoE Pre-school Education Program & 8 & 0 & 2 & 0 & 3 \\
\hline
\end{tabular}

The matching skill, one of the mathematical concepts, was observed separately according to shape, size, weight, length and quantity subcategories. It was seen that the children trained with the Montessori Approach and MoE PSP did activities mostly towards matching. However, the activities done towards matching skills were seen more frequently in children trained with the Montessori Approach than in children trained with MoE PSP.

It was observed that the children who were trained with the Montessori Approach did activities mostly towards matching skills according to shape, then the quantity (35\%), the length (10\%) and the size (5\%) respectively. All of the 48-60-month-old girls and 3 of the 61-72-month-old girl, two boys both 48-60 months and 61-72 months old were observed having matching according to shape skill. While 48-60 months old one boy and 61-72 month old one boy 
were able to match according to length, this skill was never observed in girls. Matching skill according to size was only seen in 1 of 61-72-month-old girls. No activities related to matching according to weight skill were observed.

In the children who were trained with MoE PSP, activities towards matching according to shape skill were observed mostly, then quantity and weight respectively. However, the matching skills towards length and size were not seen. In one 48-60 months old girl and one 61-72-month-old girl, all of the 48-60-month-old boys and one 61-72-month-old boy were observed to have matching according to shape skill. This skill was seen in 2 girls and one boy who was 61-72 months old, while no matching skills were found in 48-60-month-old children. Matching according to weight skill was observed in 2 boys who were 61-72-month-old.

Citations about matching skill observed in children are given below;

He did matching according to quantity with number bars and scorecards (M, 48-60, Montessori).

While working with cylinder blocks, she matched the cylinders according to their size (F, 61-72, Montessori).

While playing with matching cards, he matched the object with the number of given objects (M, 61-72, PSP).

He matched the socks mixed given in a basket by finding the suits (M, 48-60, PSP).

Grouping

Table 4. The Distribution of Children Who Do Activities towards Grouping Skills

\begin{tabular}{lccccc}
\hline \multirow{2}{*}{ Grouping } & Figure & Size & Weight & Length & Quantity \\
\cline { 2 - 6 } & f & f & f & f & f \\
\hline Montessori Approach & 13 & 4 & 0 & 0 & 6 \\
MoE Pre-school Education Program & 12 & 0 & 0 & 0 & 0 \\
\hline
\end{tabular}

The grouping skill, one of the mathematical concepts was observed separately according to the subcategories of shape, size, weight, length, and quantity. It was seen that the skill that children were trained with Montessori Approach and MoE PSP perform mostly was towards grouping according to shape. However, the activities towards grouping skills were seen more often in children trained with the Montessori Approach than in children trained with MoE PSP.

The activities towards grouping skills seen in children trained with Montessori Approach were observed mostly according to the shape, then the quantity and the size respectively. No activities towards grouping skills according to weight or length was seen. Grouping skills were observed in 3 of the 48-60-month-old girls, in 2 of the 61-72-month-old girls, in 4 of 48-60 and 61-72-month-old boys. Grouping skill according to size was seen in 1 of 48-60-month-old girls, in 2 of boys, in 1 of 61-72-month-old boys, but not in girls.

According to the amount, the grouping skill was observed in 1 of 48-60 and 1 of 61-72-month-old girls, in 2 of 48-60 and 2 of 61-72-month-old boys. While more than half (60\%) of the children who were trained with MoE PSP were found to have grouping skills according to the shape, the grouping skill according to size, weight, length, and quantity was not observed. All of the 48-60-month-old girls, 4 of the 61-72-month-old girls, 4 of 48-60 and 4 of 61-72-month-old boys were observed having grouping according to shape skill.

Citations about grouping skill observed in children are given below;

She grouped number cards and beads according to their quantity as union, decimal, hundred, and thousand (F, 6172, Montessori).

She grouped the cylinders according to their sizes and placed them in the boxes they belonged to (F, 48-60, Montessori).

When the playtime was over, she placed the Legos in boxes according to their shapes (F, 48-60, PSP).

By grouping the vehicles according to their shape, he formed a garage for the vehicles (M, 61-72, PSP).

Comparison / Ranking

Table 5. The Distribution of Children Who Do Activities towards Comparison/ Ranking Skills

\begin{tabular}{lccccc}
\hline \multirow{2}{*}{ Comparison / Ranking } & Figure & Size & Weight & Length & \multicolumn{2}{c}{ Quantity } \\
\cline { 2 - 6 } & f & f & f & f & f \\
\hline Montessori Approach & 15 & 7 & 2 & 6 & 5 \\
MoE Pre-school Education Program & 8 & 0 & 1 & 0 & 0 \\
\hline
\end{tabular}

Comparison/ranking skill, one of the mathematical concepts was observed separately according to subcategories of shape, size, weight, length, and quantity. The most observed skills in children were trained with Montessori Approach and MoE PSP was the activities related to comparison/ranking according to shape. However, the activities towards the 
comparison/ranking skill of children trained with Montessori Approach were observed more frequently than those who were trained with MoE PSP.

The activities towards the comparison/ranking skill in children who were trained with Montessori Approach observed was mostly according to shape (75\%), then followed by the size (35\%), length (30\%), and quantity (25\%) respectively. All 48-60 and 61-72 month-old girls, 2 of 48-60 month-old boys and 3 of 61-72 month-old boys were observed having comparison/ranking according to shape. While comparison/ranking according to size skill was observed in 3 girls 4860 and 61-72 months old girls and one boy 48-60 months old boy, boys of 61-72 months old did not have this skill. While comparison/ranking according to length skill was observed in 2 girls of 48-60 month-old, 1 of boys, and 3 of 6172 month-old boys, 61-72 month-old girls did not have this skill.

The comparison/ranking according to quantity skill was observed in 1 girl and one boy of 48-60-month-old, one boy of 61-72 month-old and 2 of the girls of 61-72 month-old. The comparison/ranking according to weight skill was seen in one girl and one boy of 61-72 month-old while this skill was not observed in girls and boys of 48-60 months old. While comparison/ranking according to shape skill was seen in 8 children (40\%) trained with MoE PSP, comparison/ranking skill according to size, length and quantity were not observed. While comparison/ranking skill according to shape was seen in 2 girls of 48-60 month-old, one girl of 61-72 month old and all the boys of 48-60 months old; boys of 61-72 month old did not show this skill. Comparison/ranking according to weight skill was observed only in a 61-72 monthold boy.

Citations about comparison/ranking according to weight skill in children were given below;

She compared the geometrical shapes such as triangle, square and circle according to their size (F, 48-60, Montessori).

While working with weight tablets, she compared two different weighted tablets to bring together those of the same weight (F, 48-60, Montessori).

Comparing the bay shapes (circle, square) of Legos, he put them together (M, 48-60, PSP).

He compared the geometric shapes made with chickpeas and toothpicks to the shape of his friend (M, 48-60, PSP).

Position in Space

Table 6. The Distribution of Children Who Do Activities towards Positioning in Space Skills

\begin{tabular}{lcc}
\hline \multirow{2}{*}{ Position in Space } & Direction & Close-Far \\
\cline { 2 - 3 } & f & f \\
\hline Montessori Approach & 3 & 0 \\
MoE Pre-school Education Program & 0 & 0 \\
\hline
\end{tabular}

Position in space skill, as one of the mathematical concepts, was observed according to the direction and close-far subcategories separately. While no activities towards the position in space skill (direction and close-far) were observed in children trained with MoE PSP, it was observed that the children trained with Montessori Approach had only direction skill. Three children trained with Montessori Approach had been observed having direction concept. Direction skill was observed in one boy and one girl who were 48-60 months old, and in a boy who was 61-72 months old while this skill was not seen in girls.

Citations about direction skill observed in children are given below;

While the two children were playing with the pink tower, one of the children changed the place of the pink tower saying that you placed it to the wrong place, you should place it down (M, 48-60; 61-72, Montessori).

While ordering the number cards, she placed the cards using an expression like this card should be in the bottom, on the top, on the right-left (F, 48-60, Montessori).

Measuring

Table 7. The Distribution of Children Who Do Activities towards Measurement Skills

\begin{tabular}{lcccc}
\hline \multirow{2}{*}{ Measurement } & Time & Length & Weight & \multicolumn{2}{c}{ Money } \\
\cline { 2 - 5 } & f & f & f & f \\
\hline Montessori Approach & 0 & 3 & 0 & 0 \\
MoE Pre-school Education Program & 0 & 0 & 1 & 0 \\
\hline
\end{tabular}

Measuring skill one of the mathematical concepts was observed according to time, length, weight, and money subcategories separately. It was observed that only the activities towards measuring according to length (15\%) were seen in children trained with the Montessori Approach. This skill was never seen in girls but was seen in 1 of $48-60$ boy and 2 of $61-72$ boys. 
Measuring according to weight was observed only in one boy of 61-72 month who was trained with MoE PSP. No other sub-skills were found.

Citations about measuring observed in children are given below;

He tried to measure the edge length of carpet with red-blue number bars in different lengths. For example, he brought $40+10 \mathrm{~cm}$ number bars side by side for the short edge (M, 61-72, Montessori).

While playing with an equal-arm scale, he placed the units on arm of scale to measure weight (M, 61-72, PSP).

Pattern

Table 8. The Distribution of Children Who Do Activities towards Pattern Skills

\begin{tabular}{lc}
\hline Pattern & f \\
\hline Montessori Approach & 14 \\
MoE Pre-school Education Program & 14 \\
\hline
\end{tabular}

When the results of the observations were examined, it was observed that 14 of the children trained with both the Montessori Approach and the MoE PSP did activities towards creating patterns.

In Montessori Approach, 4 of the 48-60-month-old girls, all of the 61-72-month-old girls, 3 of the 48-60-month-old boys and 3 of the 61-72 month-old boys had the ability to pattern.

While all of the 48-60-month-old children who were trained with the MoE PSP were able to create patterns, 3 of the 61 72-month-old girls and 2 of the boys had this skill.

Citations about pattern skill observed in children are given below;

She created a bracelet by arranging the colored beads as five reds, five yellows, and five blues $(F, 48-60$, Montessori).

She did pattern works with pattern cards (F, 61-72, Montessori).

She created a pattern with yellow, red and blue color while forming a rectangular with Legos (F, 48-60, PSP).

While playing with the table toys, she said that she created a hamburger with circles in different sizes different colors, then made a big hamburger by placing two large circles in the bottom and two small ones on the top $(F, 61$ $72, P S P)$.

Part-Whole

Table 9. The Distribution of Children Who Do Activities towards Part-Whole Skills

\begin{tabular}{lc}
\hline Part-whole & F \\
\hline Montessori Approach & 15 \\
MoE Pre-school Education Program & 3 \\
\hline
\end{tabular}

The activities/practices towards part-whole relationship-building skills were observed in 15 of the children trained with the Montessori Approach, and in the 3 of the children trained with MoE PSP. According to this, it was determined that the activities towards part-whole relation-building skills were seen more in children who were trained with Montessori Approach than children who were trained with MoE PSP.

In Montessori Approach, 3 of the 48-60-month-old girls, all of the 61-72-month-old girls, 48-60 and 61-72-month-old 4 boys were observed to be able to establish a part-whole relationship. While no part-whole relationship-building skill was observed in 61-72-month-old children who were trained with MoE PSP, 2 of the 48-60-month-old girls and 1 of the boys were observed having this skill.

Citations about part-whole relationship-building skill observed in children are given below;

She gathered the colored triangular parts into larger triangles ( $F, 48-60$, Montessori).

She placed the tangram pieces correctly in the box (F, 48-60, Montessori).

She completed a face puzzle divided into four parts (F, 48-60, PSP).

She gathered two or three-piece wooden geometric shapes (F, 48-60, PSP).

Transactions

Table 10. The Distribution of Children Who Do Activities towards Transactions Skills

\begin{tabular}{lcc}
\hline \multirow{2}{*}{ Transactions } & Increase & Reduction \\
\cline { 2 - 3 } & f & f \\
\hline Montessori Approach & 5 & 3 \\
MoE Pre-school Education Program & 4 & 2 \\
\hline
\end{tabular}


Transaction skills were observed separately according to the subcategories of increase-proliferation and decreasereduction. It was seen that 5 of the children who were trained with Montessori Approach did addition, and 3 of them did subtraction. It was determined that 48-60 month-old girls did not do any addition or subtraction, 2 of the 61-72 month-old girls did addition, and 1 did subtraction. It has been observed that 2 of the 48-60-month-old boys did addition, one did subtraction and one boy at 61-72 months old did addition and one subtraction.

It has been observed that 4 of the children who were trained with MoE PSP did addition and 2 of them did subtraction. It has been determined that children aged 48-60 months did not do addition and subtraction, while two girls and two boys aged 61-72 months did addition, and one boy and one girl boy did subtraction.

Citations about the transaction skill observed in children are given below;

He did addition and subtraction using collecting bowl and beads (M, 48-60, Montessori).
She did addition with number cards (F, 61-72, Montessori).
He did addition with number cards and objects (M, 61-72, PSP).
She used the geometric shapes on the magnetic board for subtraction (F, 61-72, PSP).

Creating Graphic

When observations results were examined, it was observed that none of the children trained with both the Montessori Approach and MoE PSP performed activities towards graphing skills.

\section{Discussion and Conclusion}

As a result of observations during the investigation of process, it was determined that children who were trained with Montessori Approach and MoE PSP did activities/practices mostly towards rhythmic counting and pattern skills. Similarly, Taskin (2013) as a result of his study in which he investigated the daily conversations of the preschoolers had encountered mostly rhythmic counting and mathematical concepts. However, pre-school teachers' conducting activities mostly towards number concept might have led them to perceive numbers first when they were said mathematics. When the literature was examined, studies supporting this view were also found (Pekin and Avci, 2016, Tarim and Bulut, 2006; Thiel, 2010). The fact that activities towards patterning skills were seen more frequently, according to the results of observation, can be explained with children's being more active in activities such as stringing which requires hand skill and the attractiveness of activities related to colors. Also, pre-school teachers who are applying MoE PSP offered children table toys which were oriented with pattern skills that this could also be seen as a reason for this.

As a result of the research, it was determined that the mathematical concept skills which were rarely seen at children trained with both Montessori Approach and MoE PSP during observation were measurement and transaction skills. Besides, in both groups, only boys did activities towards measurement skill. Likewise, Taskin (2013), as a result of his study about the children at the pre-school period, found the least encountered mathematical concept as measurement according to children's learning areas. As a result of observation, it was seen that only the children at the age of 61-72 months old trained with MoE PSP did activities directed to operation skills. It was noteworthy that even if the children did activities towards rhythmic counting skill during observation, the activities towards transaction skills observed less frequently, however when the age groups and developments characteristics were taken into consideration, it could be said that this was an expected result.

As a result of the observations obtained, no activities towards graphing skills were found in either group. Also, there were no activities towards the position in space skill in the children trained with MoE PSP. Only the direction skill activities which were one of the positions in space skills were observed in the children trained with Montessori Approach. It was thought that because of including fewer activities towards the position in space and graphing in the daytime at classes where MoE PSP is applied and having fewer materials that could be used at these activities, these skills were not taught. Nevertheless, the fact that these skills were scarce in the class where Montessori Approach was applied was considered as a significant result.

When the results of the research were investigated, it was seen that more activities towards matching according to shape, grouping, and comparing/ranking sub-skills were done in both groups. The reason for this was that there were more activities for these skills and there were more play materials used in these activities. On the contrary, the subskills related to activities towards matching according to weight; grouping according to weight and length; close-far; measurement according to weight and money were not seen at children trained with Montessori Approach. At the same time, the activities towards sub-skills related to matching according to size and length; grouping according to size, length, weight and quantity; comparison according to size, length and quantity; measurement according to time, length and money were not seen at children trained with MoE PSP. In addition to this, observing the part-whole skill only in 48-60-month-old children group who were trained with MoE PSP was considered as a significant result. This could be explained by the fact that the teachers in these classes offered more play materials for this skill whereas in the class with the children who are 61-72 months old these materials were not presented to the children. It was seen as a disadvantage that in classes where MoE PSP was applied, the play materials were kept in the boxes which children 
could not reach, teachers' presenting these materials to children at playtime and inability of children to play all the materials as they want.

When evaluated in general, it was seen that more activities towards mathematical concept skills were done in classes where the Montessori Approach was applied when compared to classes where MoE PSP was applied. It was seen that the children trained with Montessori Approach did more activities related to especially matching, grouping, comparing/ranking and part-whole skills. When the literature was reviewed in parallel to this, it was determined that the children trained with Montessori Approach were much more successful at mathematical skills than those who did not (Aydogan and Sen, 2011; Faryadi, 2017; Hobbs, 2008; Kayili and Ari, 2011; Ongoren, 2008; Toran and Temel, 2014; Yigit, 2008; White, Yussen and Docherty, 1976). It can be said that the variety of training materials presented to children and doing activities that develop children's mathematics skills in Montessori Approach led to observation of more mathematical concept skills in the children at this group. The fact that the play materials towards mathematical concept skills were limited, the availability of toys such as cars, dolls, and Lego in the educational environment and the inadequacy of the mathematical activities in classes where MoE PSP was applied might be the cause of observing these skills less.

In the light of the results obtained in this research, it is essential to enrich the classes where MoE PSP applied in terms of play materials for mathematical concept skills and to select and place the classroom play materials by the development characteristics of the children. It is suggested that the play materials that had to be in classes where MoE PSP was applied should be standardized and children could reach these materials also mathematics center should be established in the class. Preschool teachers are also expected to guide children in the development of mathematical concept skills by giving more space to mathematical activities in the day. Children's doing different activities towards mathematical concept skills will help them to make connections between conceptual information and new information and to understand why and how mathematical concepts are used. On the other hand, to disseminate the Montessori Approach, pre-school teachers may be given training seminars on this topic so that teachers know Montessori materials.

\section{References}

Aydogan, S., \& Sen, S. (2011). The effects of concept teaching programme on 6-year-old children's number concept development. Adnan Menderes University Faculty of Education Journal of Educational Sciences, 2(1), 38-51.

Buyuktaskapu, S. (2011). Montessori materyalleri [Montessori materials]. In E. Cakiroglu-Wilbrandt (Eds.), Okul oncesi egitimde Montessori yaklasimi [Montessori Approach in pre-school education]. Ankara: Kok Publishing.

Durakoglu, A. (2010). Reading and writing education in Montessori method. Family \& Society Journal of Education, Culture and Research, 11(5), 91-104.

Erdogan, S. (2016). Okul oncesi donemde matematik programi [Mathematics program in pre-school period]. In B. Akman (Eds.), Okul oncesi matematik egitimi [Preschool mathematics education]. Ankara: Pegem Akademi Publishing.

Faryadi, Q. (2017). The application of Montessori method in learning mathematics: an experimental research. Open Access Library Journal, 4, 1-14.

Hobbs, A. (2008). Academic achievement: Montessori and non-Montessori private school settings (Unpublished doctoral dissertation). University of Houston, Houston, USA.

Haylock, D. \& Cockburn, A. (2014). Kucuk cocuklar icin matematigi anlama (Understanding mathematics for young children) (Z. Yilmaz, trans.). Ankara: Nobel Akademi Publishing.

Kandir, A., Can Yasar, M., Yazici, E., Turkoglu, D., \& Yaman-Bayindir, I. (2016). Erken cocukluk egitiminde matematik [Mathematics in early childhood education]. Istanbul: Morpa Publications.

Kayili, G., \& Ari, R. (2011). Examination of the effects of the Montessori method on preschool children's readiness to primary education. Educational Sciences: Theory \& Practice, 11(4), 2091-2109.

Ministry of Education. (2013). Pre-school education program. Ankara: Ministry of Education.

Merriam, S. B. (2013). Nitel arastirma [Qualitative research] (S. Turan, trans.). Ankara: Nobel Akademi Publishing.

Miles, M. B., \& Huberman, A. M. (1994). Qualitative data analysis. Thousand Oaks, CA: Sage.

Mutlu, B., Ergisi, A., Butun-Ayhan, A. \& Aral, N. (2012). Montessori education in pre-school period. Journal of Ankara Health Sciences, 1(3), 113-128.

Oguz, V. \& Akyol, A. (2006). Cocuk egitiminde Montessori yaklasimi [Montessori Approach in child education]. Journal of Cukurova University Institute of Social Sciences, 15(1), 243-256. 
Ongoren, S. (2008). The effectiveness of Montessori education method on the acquisition of geometrical shapes concepts to 4-5-year-old children in preschool (Unpublished master's thesis). Selcuk University, Konya, Turkey.

Pekince, P., \& Avci, N. (2016). Pre-school teachers' applications related to early- childhood mathematics: a qualitative look at activity plans. Kastamonu Education Journal, 24(5), 2391-2408.

Tarim, K. \& Bulut, S. (2006). Okul oncesi ogretmenlerinin matematik ve matematik ogretimine iliskin algi ve tutumlari (Preschool teachers 'mathematics and mathematics teaching performance and attitudes). Cukurova University Faculty of Education Journal, 2, 32-65.

Taskin, N. (2013). An investigation on the relation between language and mathematics during preschool (Unpublished doctoral dissertation). Hacettepe University, Ankara, USA.

Thiel, O. (2010) Teachers' attitudes towards mathematics in early childhood education. European Early Childhood Education Research Journal, 18(1), 105-11.

Toran, M., \& Temel, Z. (2014). Examining the effects of the Montessori Approach on children's concept acquisition. Elementary Education Online, 13(1), 223-234.

Unal, M. (2016). Matematiksel kavram gelisiminde eslestirme, siniflandirma, gruplama, karsilastirma, siralama [Matching, classifying, grouping, comparing, sorting in mathematical concept development]. In B. Akman (Eds.), Okul oncesi matematik egitimi [Preschool mathematics education]. Ankara: Pegem Akademi Publishing.

White J. M., Yussen, S. R., \& Docherty, E. M. (1976). Performance of Montessori and traditionally schooled nursery children on tasks of seriation, classification, and conservation, contemporary. Educational Psychology, 1, 356-368.

Wilbrandt-Cakiroglu, E. (2009). Maria Montessori yontemiyle cocuk egitimi sanati, egitimciler ve ebeveynler icin el kitabi [The art of children's education by Maria Montessori Approach, a handbook for educators and parents]. Istanbul: Sistem Publishing.

Yigit, T. (2008). Comparison of gaining number concept of children who are trained via Montessori and traditional methods in preschool institutions (Unpublished master's thesis). Selcuk University, Konya, Turkey.

Yin, R. K. (2008). Case study research: Design and methods. Thousands Oaks, CA: Sage. 